\title{
Dynamics of the Black Sea Upper Layer Based on Satellite Data: Gridded Altimetry versus High Resolution IR Images
}

\author{
A. I. Mizyuk*, G. K. Korotaev \\ Marine Hydrophysical Institute of RAS, Sevastopol, Russian Federation \\ *artem.mizyuk@mhi-ras.ru
}

Purpose. During more than 20 years, very detailed notions of the sea level variability in the World Ocean and its particular parts have been obtained based on satellite altimetry observations. Their advantage consists in possibility of a fairly rapid assessment of the surface currents' velocities at meso scales. The alternative method for studying surface dynamics is motion estimation using a sequence of visible/infrared (IR) satellite images of the sea surface. The purpose of the present study is to compare the results obtaineds from application of two described methods used to analyze general circulation of the Black Sea surface layer.

Methods and Results. The structure of the current fields in the northwestern Black Sea in winter, 1999 is investigated using the results of analysis of the IR image sequence from the NOAA/AVHRR sensors, as well as the gridded sea level anomaly (SLA) data (processing level L4) and the along-track measurements (level processing L3) from the Copernicus Marine Environment Monitoring Service. The surface currents' velocities are estimated based on the sea level field, which is calculated using two versions of mean dynamic topography. To compare the gridded altimetry and the results of the image sequence processing, a simple procedure is proposed for reconstructing the sea level using the current velocities' components.

The results of reconstructing the surface circulation features by two methods were compared and demonstrated, in particular, the anticyclonic eddy locations in the northwestern part of the Black Sea. It is noted that the locations of the eddy center in the sea level fields reconstructed from the altimetry data and by processing of the IR image sequence are different. Evolution of the eddy is investigated using the SLA data. It is shown that its motion is rather intermittent in time that can be a result of applying the procedure of optimal interpolation.

Conclusions. It is noted that the gridded satellite altimetry product from the CMEMS, being applied to the Black Sea basin, should be used with due regard for the provided information on the mapping errors.

Keywords: satellite altimetry, image sequence analysis, motion estimation, mesoscale variability, Black Sea, Copernicus.

Acknowledgements: the authors are thankful to the Head of the Remote Sensing Department, FSBSI MHI, Ph.D. S.V. Stanichny for providing satellite IR images of the NOAA/AVHRR sensors. The investigation is carried out in Marine Hydrophysical Institute, RAS, with financial support of the Russian Science Foundation (grant No. 17-77-30001).

For citation: Mizyuk, A.I. and Korotaev, G.K., 2019. Dynamics of the Black Sea Upper Layer Based on Satellite Data: Gridded Altimetry versus High Resolution IR Images. Physical Oceanography, [e-journal] 26(3), pp. 214-224. doi:10.22449/1573-160X-2019-3-214-224

DOI: 10.22449/1573-160X-2019-3-214-224

(c) 2019, A. I. Mizyuk, G. K. Korotaev

(C) 2019, Physical Oceanography

\section{Introduction}

The ocean dynamics studies are mainly based on observational data. Since the beginning of the 90s of the XX century, a number of sea surface observations from satellites has significantly increased providing the detailed study of the variability of marine basins' fields. 
Of particular note are satellite altimetry measurements, which provide information about an important parameter - sea surface height $(\mathrm{SSH})$ - that characterizes geostrophic currents in the ocean upper layer. Since 1992, a large number of satellites equipped with altimeters have been launched [1, 2]. As the cloudiness does not interfere with these measurements, they are uniform in space and regular in time. This is especially important for such areas as the Black Sea, where in the mid-90s ship oceanographic observations were almost not carried out.

Over a period of more than 20 years, a detailed picture of the World Ocean sea surface height variability and its separated water areas has been obtained [3-5] within the framework of AVISO+ project (https://www.aviso.altimetry.fr/), based on altimetry observations. Subsequently, the altimetry observations accumulated under this project and the products derived from them were incorporated into the Systems of Continuous Ocean Nowcasting and Forecasting (SCONF), for example, Copernicus Marine Environment Monitoring Service* (CMEMS) within the framework of thematic assembly centers. The altimetry data assimilation within the general ocean circulation models can significantly improve the quality of analysis and forecast of the ocean state [6, 7].

The major benefit of altimetry measurements is the ability for quick estimation of surface currents velocity based on the equations of geostrophic balance [8, 9], which is well performed far from the coast.

CMEMS Satellite Altimetry Center provides a DUACS ** dataset (Data Unification and Altimeter Combination System) containing along-track and gridded data for the global ocean (with resolution of $14 \mathrm{~km}$ and $0.25^{\circ}$ respectively). Products with improved spatial resolution for certain basins are also prepared. Their horizontal resolution for the Black Sea is $7 \mathrm{~km}$ and $0.125^{\circ}(\approx 14 \mathrm{~km})$. This resolution is sufficient for the studies of the deep-sea part mesoscale variability, where the internal baroclinic Rossby radius of deformation is within 20-25 km range [10].

An alternative method for studying surface currents on scales above $200 \mathrm{~m}$ is based on the use of visible or infrared (IR) satellite images of the sea surface. The field of current velocities is reconstructed as a result of cloudless image sequence processing of under the assumption that the image brightness is transferred by the currents. In this case, the transport-diffusion equation is usually used [11-14] in order to describe the transfer of contrasts in the radiation field.

In [13], the reconstruction of the velocity of surface currents is based on the procedure of variational data assimilation using adjoint equations. On the basis of the proposed method, according to the data on the radiation brightness for certain regions of the Black Sea, the maps of current velocity and radiation temperature fields were constructed. The reconstructed currents turned out to be more intense than those estimated from altimetry data.

In this paper, an additional analysis of the velocity field of currents obtained in [13] was carried out to compare it with the satellite altimetric measurements of $\mathrm{SSH}$. It is shown that in the Black Sea the DUACS/CMEMS altimetry products on a regular grid may misinterpret mesoscale processes in the areas where AES tracks are relatively rarely distributed in time and space.

* URL: http://marine.copernicus.eu/ [Accessed: 30 April 2019].

** URL: https://duacs.cls.fr/ [Accessed: 30 April 2019]. 
In the Section 2 the arrays (including current velocities) obtained as a result of applying the algorithm of variational assimilation from [13], are described. The arrays were used to analyze one of the events of the manifestation of Sevastopol anticyclone. A simple procedure for estimating the SSH field from the results of image sequence processing was proposed and implemented. Section 3 analyzes in detail the features of the spatial variability of the sea level anomaly (SLA) fields, constructed from gridded satellite altimetry data and calculated on the basis of processing of IR images. The last section is devoted to a discussion of the comparison results and some features of the procedure used for an objective analysis of an array of sea level anomalies.

\section{Data and methods}

In this work, a typical pattern of currents in the upper layer in the northwestern part of the Black Sea in December 1999 is studied using various observational data*. The main array that provides an estimation of the velocities for the studied region are the DUACS gridded sea level anomalies ( $L 4$ processing level) of CMEMS ** system [15]. An array distributed in the "delayed time" mode (reprocessing) is used. With such a processing procedure, it becomes possible to refine the fields of anomalies by engaging the data for constructing the maps which are formally the future data (relative to the current date). Thus, the result for the current day is constructed with the involvement of previous and subsequent altimetry measurements. The interpolation procedure is given in [16], and the main parameters and analysis of the results of its use for the ocean - in [15]. We note that the latter work do not present the correlation scales separately for the Black Sea. The authors failed to find more detailed information for this region, and it can be assumed that such a study for the Black Sea basin was not performed apart from the global ocean. The output resolution of the product is $0.125^{\circ} \times 0.125^{\circ}$, which is $\approx 14 \mathrm{~km}$ in the meridional direction.

In order to determine the velocities of surface currents we require a field of sea surface height, which can be calculated using a simple formula: $\zeta_{D U A C S}=\zeta_{\mathrm{a}}+\langle\zeta\rangle$, where $\zeta_{\mathrm{a}}$ is a sea level anomaly (SLA), $\langle\zeta>$ is a mean dynamic topography (MDT). It is assumed that MDT is some invariant surface constructed by averaging information about the sea level over a long period [9]. The satellites measure the value of the elevation (anomaly) from this surface. Such a topography based on archival hydrological measurements was constructed in [17] (MDT 1$)$.

Another way for determining MDT is time averaging of the results of longterm numerical simulations of climatic circulation with the observational data assimilation. For this, we used here an array from [18] $\left(\mathrm{MDT}_{2}\right)$. The differences in the mentioned invariants for the studied part of the Black Sea are shown in Fig. 1. $\mathrm{MDT}_{1}$ and $\mathrm{MDT}_{2}$ arrays have similar structures in the form of the Eastern cyclonic gyre. At the same time, $\mathrm{MDT}_{1}$, based on measurements is characterized by higher coast-to-sea gradients.

* The study was carried out using the data of Copernicus Marine Service EU.

** URL: http://marine.copernicus.eu/ [Accessed: 31 April 2017]. 


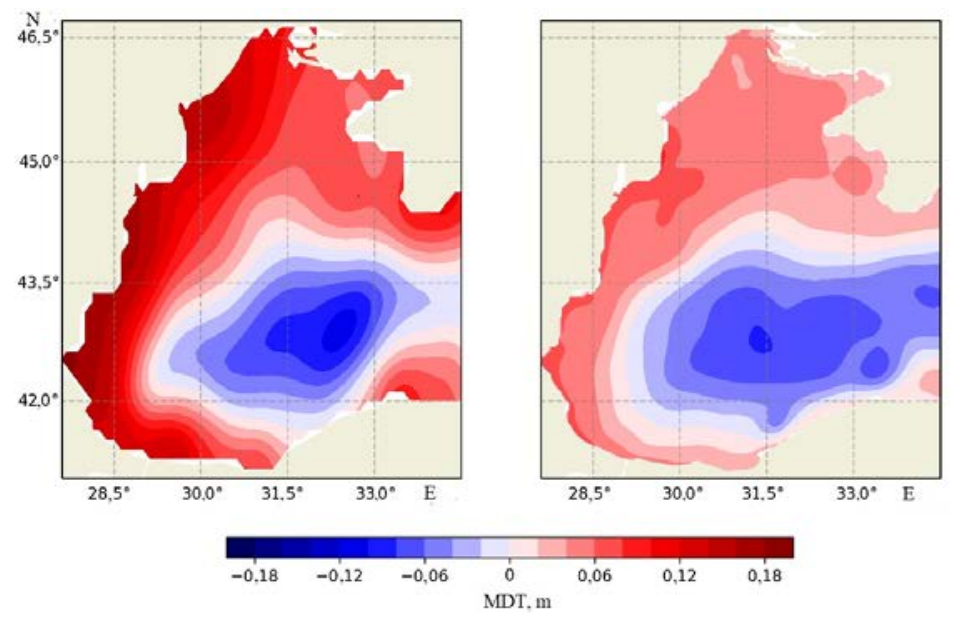

F i g. 1. Mean dynamic topography (m) in the western Black Sea: on the left - based on the measurements from [17]; on the right - from numerical modeling results [18]

We analyzed the results of applying the both methods for calculating MDT (Fig. 2). The use of MDT different variants did not qualitatively affect the reconstructed fields of the total sea level. It can be seen that the structures of the level fields are qualitatively similar. It should be pointed out that the eddies in the maps are reconstructed only due to the use of DUACS/CMEMS L4 SLA data, since there is no such structures in MDT fields. The differences in numerical values can be observed. The difference is especially noticeable off the Romanian coast; it is caused by a large gradient in the field of $\mathrm{MDT}_{1}$ between the deep and coastal parts of the sea.
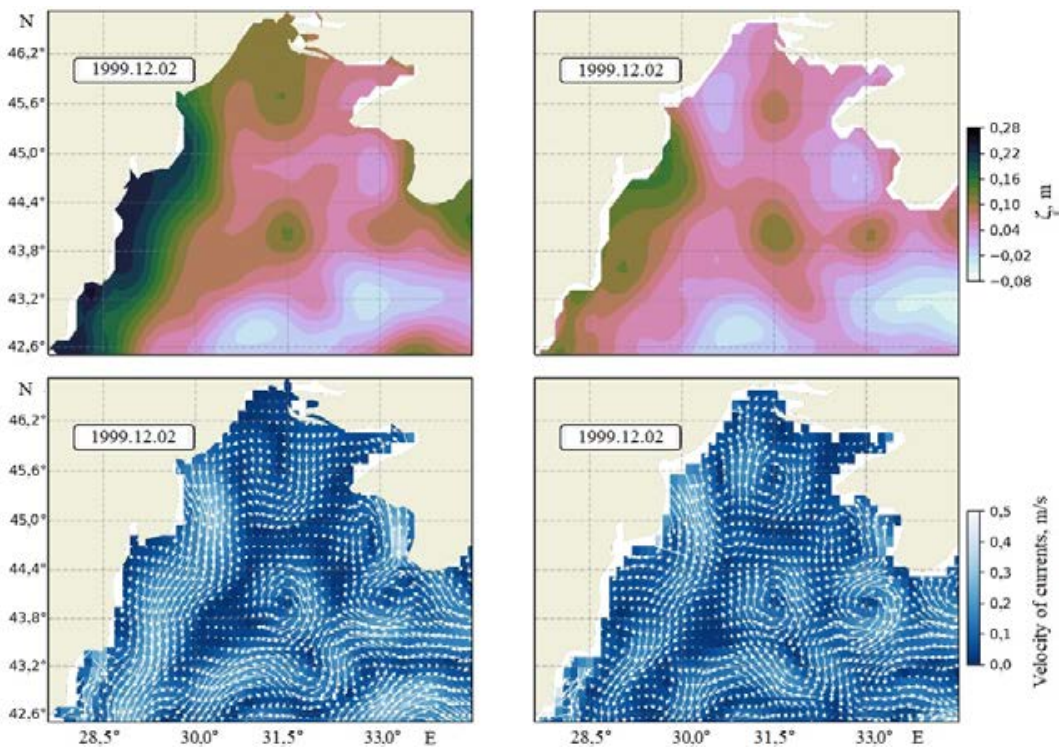

F i g. 2. Sea surface height (m) (above) and obtained current velocities (m/s) (below) based on the DUACS/CMEMS L4 and MDT 2 measurements [17] (on the left) and the DUACS/CMEMS L4 and MDT 1 ones [18] (on the right). The currents' direction is shown by the arrows; the scale of the arrows' lengths is the same. 
The current velocities were estimated based on the equations of geostrophic balance

$$
\begin{aligned}
& u_{g}=-\frac{g}{f} \frac{\partial \zeta_{D U A C S}}{\partial y}, \\
& v_{g}=-\frac{g}{f} \frac{\partial \zeta_{D U A C S}}{\partial x},
\end{aligned}
$$

where $u_{g}, v_{g}$, are geostrophic velocities of currents; $g$ is a free-fall acceleration; $f$ is the Coriolis frequency. The visualization of the field of current velocity confirms the matching of the SSH fields (Fig. 2, below) more clearly. The position of eddies and the direction of their rotation mainly coincide on the obtained maps, except for the coastal region of the northwestern shelf. Here, as noted earlier, the accuracy of altimetric arrays is poor and the geostrophic balance is not satisfied. A larger gradient off the Romanian coast formed only a more intensive alongshore current, while the structures of the velocity fields for $\mathrm{MDT}_{1}$ and $\mathrm{MDT}_{2}$ in the noted water area are in rather good agreement. The analysis of the SSH time series on other dates showed a similar picture. Since the analysis results did not differ fundamentally, satellite images [13] are compared with altimetry measurements (obtained with $\mathrm{MDT}_{2}$ ).

The features of the objective analysis procedure used to reconstruct the gridded sea level anomalies were studied involving along-track altimetry measurements DUACS * of CMEMS service of L3 processing level. This array, like DUACS/CMEMS $L 4$, is a reprocessing and is provided in a "delayed time” mode. In this paper, we used the data for November - December 1999. Their spatial resolution is $7 \mathrm{~km}$.

During this period, the measurements were carried out by ERS-2 and TOPEX/Poseidon (T/P) satellites. ERS-2 tracks cover the sea area denser than $T / P$ tracks, with about $60 \mathrm{~km}$ distance between the tracks. The distance between $T / P$ tracks is more than three times higher (Fig. 3, a) in comparison with the ERS-2 tracks. In Fig. 3, b, the histograms of the measurement distribution are shown for the period under study for each of the satellites, since the spatial position of the measurements does not allow us to get a full representation of the available data. Note that the amount of ERS-2 data is approximately 20\% higher than the T/P data (547 and 447 measurements, respectively).

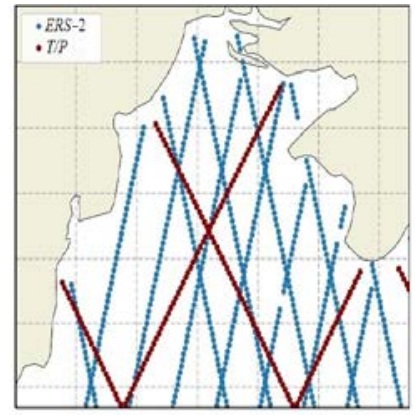

$a$

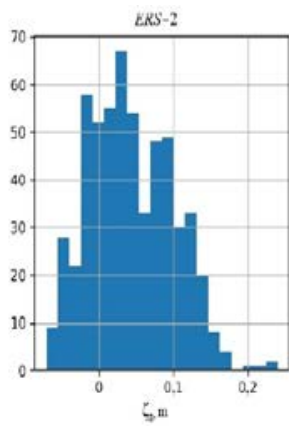

$b$



$b$

F i g. 3. DUACS/CMEMS altimetry measurements in November-December, 1999 along the ERS-2 and $T / P$ tracks in the region under study: $a$ - spatial position of the measurements' tracks; $b-$ histograms of the measurements' distribution for the whole period for each satellite

* URL: http://marine.copernicus.eu/ [Accessed: 23 March 2017]. 
NOAA/AVHRR scanning IR-radiometer data serve as an independent source of information on the structure of currents in the studied area. An algorithm for estimating the velocities of currents based on sequential images, noted earlier, was proposed in [13]. In Fig. 4, $a$, a fragment of an image from a series for December 2, 1999 is demonstrated. Due to $1 \mathrm{~km}$ spatial resolution, a number of manifestations of mesoscale processes can be revealed both in the shelf zone and in the deep sea area. A large number of dynamic structures off the Anatolian coast are distinct in the image. The formation of the Sevastopol anticyclone is observed at the southwestern edge of the Crimean Peninsula. A somewhat earlier formed, more pronounced anticyclonic eddy has already broken away from the coast and moves along the continental slope. In the figure it is highlighted by a dotted rectangle, a zoom of the selected area is shown in Fig. 4, $b$. Closer examination shows smaller spatial structures here. The field of current velocities, reconstructed as a result of applying the algorithm from [13], is also presented in Fig. 4, $b$. Note that the velocities of currents are correspond well enough with the satellite image.
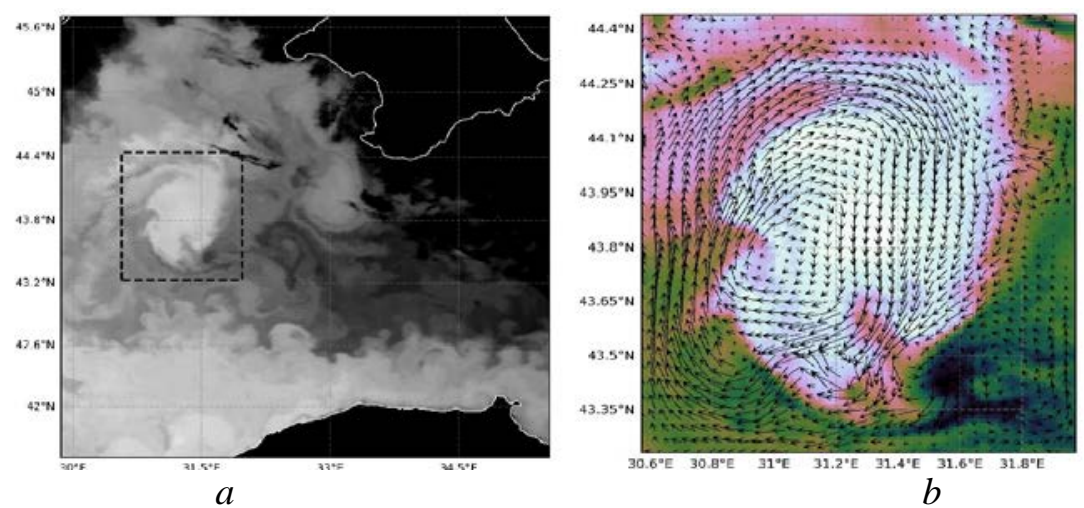

F $\mathbf{i}$ g. 4. Brightness temperature of the sea surface based on the NOAA/AVHRR sensor data on December 2, 1999 [13] (a); zoom of the marked area (gradient) and the reconstructed fields of the current velocities [13] (arrows) (b)

The accuracy of the fields reconstructed by the algorithm from [13] is confirmed by the fact that in the investigated area in the fields of sea surface heigh and geostrophic velocities according to DUACS L4 for the same date, an anticyclonic eddy is also observed (see Fig. 2). Comparison of its position according to the DUACS $L 4$ data with the results of the analysis of IR images, as well as a detailed comparison of two level fields, will be discussed in Section 3.

It is convenient to compare mapped DUACS/CMEMS arrays and NOAA/AVHRR IR-image processing results if the sea level is reconstructed using information on the horizontal components of the velocity of currents. For this, we use the following relations. We introduce a stream function $\psi$ such that

$$
u=\frac{\partial \psi}{\partial y}, \quad v=\frac{\partial \psi}{\partial x} .
$$

Then we use an equation of stream function calculation from the vorticity of the flow

$$
\Delta \psi=\omega,
$$


where $\omega$ is a vorticity which, in our two-dimensional case, has only z-component: $\omega_{z}=\frac{\partial v}{\partial x}-\frac{\partial u}{\partial y}$. Equation (2) is the elliptic Poisson's equation. To solve it, the Neumann condition was prescribed at boundaries. The equation was solved numerically by the finite difference method. The iterative solution procedure used 20000 iterations. At the same time, the evolution of the $s$ area averaged difference between the solutions of equation (2) at time moments $n$ and $(n-1)$ shows that at time moment $n \approx 16000$ the solution approximately reached a stationary state with a deviation value $\varepsilon<=1 \cdot 10^{-3} \mathrm{~m}^{2} / \mathrm{s}$ (Fig. $5, a$ ).

In order to verify the procedure accuracy, we estimated the components of the current rates $u_{\text {est }}$ and $v_{\text {est }}$ from the calculated stream function using type (1) relation. The variance modules $\left|u-u_{\text {est }}\right|$ and $\mid v-v_{\text {est }}$, presented in Fig. 5, $b$, were chosen as a characteristic of the estimation errors. As can be seen, the calculated velocities agree well with the results of [13]. The difference is observed only in the areas with pronounced small-scale structures. The standard deviations (RMSD) of the calculated velocities from the estimates of [13] do not exceed $0.0142 \mathrm{~m} / \mathrm{s}$.

Sea level is expressed through the stream function according to the formula

$$
\zeta=\frac{f}{g} \psi
$$

For comparison with the mapped SSH obtained from the DUACS/CMEMS arrays, the spatial average was subtracted from the given characteristic.
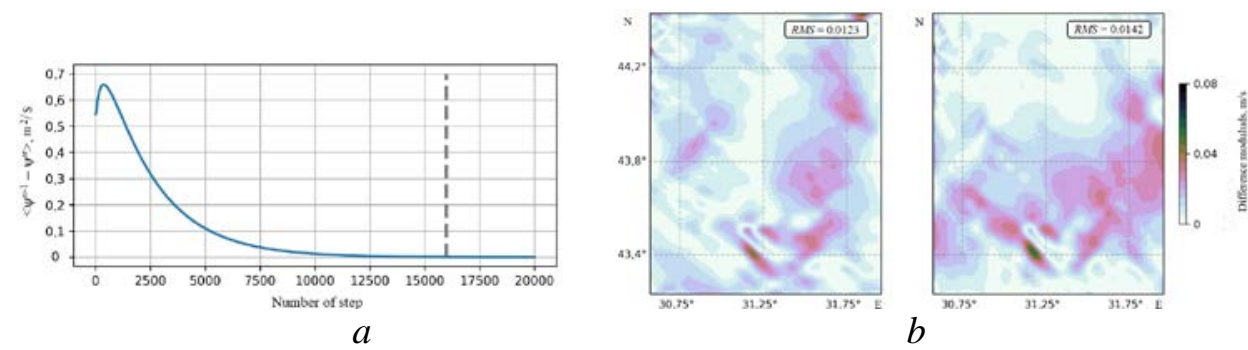

F i g. 5. Convergence estimation and accuracy analysis of the stream function calculation: $a-$ evolution of the area-average difference of the current functions $\left(\mathrm{m}^{2} / \mathrm{s}\right)$ at the time moments $n$ and $(n-1)\left(\varepsilon=\psi^{n}-\psi^{n-1}\right) ; b-$ absolute differences $\left|u-u_{\text {est }}\right|$ (to the left) and $\mid v-v$ est $\mid$ (to the right)

\section{Results}

We consider in more detail the SSH reconstructed from equation (3), together with the velocity fields from [13]. Both fields are in rather well agreement with the temperature field (Fig. 6, $a ; 4, b$ ). This can be represented by the isotherm highlighted on the map (red isoline), which reflects the movement of water masses along the periphery with the formation of smaller-scale dynamic structures. For example, in the northern part of Fig. 6, $a$, a cold filament of $80 \mathrm{~km}$ length, stretched along the level isolines, i.e. along the direction of water movement, is located. Another filament (about $43.8^{\circ} \mathrm{N}, 30.8^{\circ} \mathrm{E}$ ) is probably located close to the eddy center, since it has a small length $(20 \mathrm{~km})$. Its small size corresponds to low velocity at this point (Fig. 6, a). The local temperature minimum can also be observed in the southeastern part of the studied area. A possible cause for this may 
be a small-scale cyclonic eddy, which is observed in the fields of current velocities and in the SSH field.

Now we consider the spatial variability of the SSH field according to the DUACS/CMEMS data (see Fig. 4, b). For illustrative purposes, some SSH isolines calculated from the values of current velocities from [13] are plotted on the map. The mapped satellite altimetry data shows that the position of the eddy is shifted to the northeast relative to the center of the warm water spot in the satellite image. Small-scale structures in the fields of satellite altimetry do not appear, and the fields themselves look quite smoothed. Recall that the eddy manifests itself in the SSH field only when anomalies from the DUACS archive are taken into account, since there are no eddy structures in the MDT in this area (see Fig. 3; $6, a)$. The center of the eddy in the field of anomalies is shifted to the periphery of the warm water spot (Fig. 6, $c$ ). Adding the MDT surface to the SLA field only slightly changed its position. (Fig. 6, $b, c$ ).


F i g. 6. Comparison of the results of the IR images and DUACS/CMEMS L4 data processing: $a-$ surface temperature and sea surface height (black isolines) on December 2, 1999 based on the NOAA/AVHRR scanner data from [13]; $b$ - sea surface height (black isolines) based on the DUACS/CMEMS and MDT2 data; $c$ - gridded sea level anomaly based on the DUACS/CMEMS data.

We also consider the retrospective analysis results of the Black Sea hydrological fields. When carrying out this analysis, the data of along-track altimetry measurements in the model of basin water circulation were assimilated. The SSH field, constructed as a result of reanalysis, corresponds to the altimetry reconstructed on a regular grid using interpolation. The coefficient of cross-correlation of fields reaches 0.7. Here a displacement in the SSH field structure relative to the temperature field is also observed. Note that when carrying out both reanalysis and interpolation, altimetric observations are used both before and after the current point in time.

To find out the cause of the discrepancy between the positions of eddy center in the SSH fields, constructed according to altimetry data and by processing an IR-image sequence of the sea surface we study its evolution in the field of sea level anomalies. The analysis of sequential maps showed that at certain time moments an intermittent displacement of the eddy center occurs (Fig. 7). This is caused by a poor distribution in time and space of along-track measurements (see Fig. 4). The lack of spatial and temporal coverage of tracks for mapping to a regular grid of such resolution is increased by using of space-time Gaussian correlation function with the parameters typical for the ocean scales. 

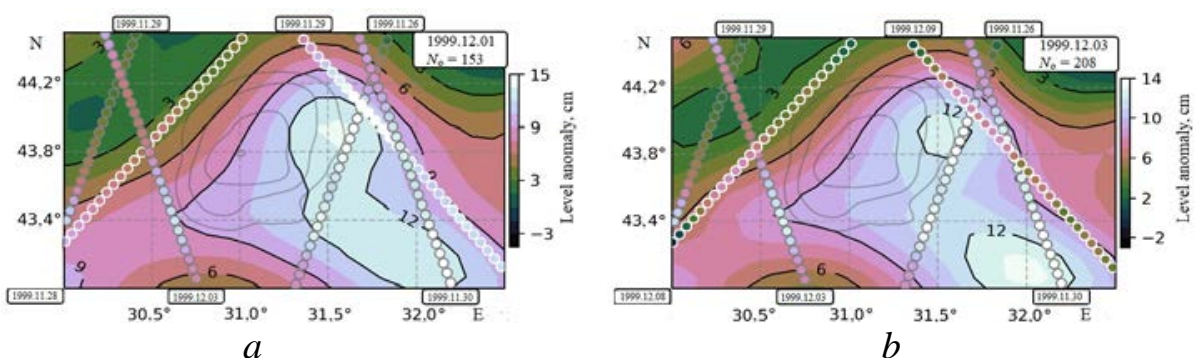

a


F i g. 7. Evolution of the sea level anomalies' field (cm) based on the DUACS/CMEMS data in early December, 1999 for the water area under study. The step of the black isolines is $3 \mathrm{~cm}$. Circles denote positions of the observations along the satellite tracks: with grey outline - the ERS-2 satellite, with white outline - the $T / P$ satellite. $N_{0}$ - number of measurements within the time period \pm 7 days from a current date. Grey isolines - the eddy position based on the NOAA/AVHRR data [13]

The anticyclone under study is also observed on the SLA map on December 1, 1999 (Fig. 7, a). In Fig. 7 along-track altimetric measurements that fall in a time period of \pm 7 days are represented for each date. This period was selected for representativeness, since here the measurements will have a relative weight above 0.8 . It is obvious that such a structure in the field of anomalies was manifested due to the presence of tracks of altimetric satellites in the northeastern part of the area under study: three tracks intersect near the point $\left(44^{\circ} \mathrm{N}, 31.75^{\circ} \mathrm{E}\right)$. Thus, we can explain the eddy displacement in the northeastern direction, which was noted earlier. The eddy intensity decreases by December 3 (Fig. 7, $b$ ) due to the fact that one of the marked $E R S$-2 tracks has less weight during the interpolation procedure. On December 12, 1999, we observe the occurrence of a new T/P satellite track in the eastern part of the map. In Fig. 7, $b$, the new track overlaps the previous ones from T/P and from ERS-2. It is obvious that it contains new measurement values.

" $12 \mathrm{~cm}$ " isoline inside the studied anticyclone disappears in the image from December 5 (Fig. 7, c), which indicates the effect of the obtained information on the result of the interpolation procedure. In the southwestern part of the water area, due to the contribution of ERS-2 measurements, which were present on the maps before, the formation of a new dynamic structure is observed. However, here the weight of these measurements increases. The configuration of the satellite trajectories is changing, their amount becomes smaller. A new eddy in the southeastern part is finally formed in the SLA field already on December 7. The intensification of this eddy and the complete disappearance of the initial one, observed in the field of anomalies earlier, can be observed already on December 9 (Fig. 7, $d$ ). We can see that on December 5-9 there are no tracks that would cover the central region of the map (from $31^{\circ} \mathrm{E}$ to $31.5^{\circ} \mathrm{E}$ ) in our time window (14 days). Obviously, the interpolation error in this area should be significant. 
In general, the presented fields of SLA demonstrate the anticyclone movement which looks somewhat unnatural. It is impossible to determine accurately whether these two structures (Fig. 7, $c$ and $d$ ) are a manifestation of one process or two different ones occurring one after another.

\section{Discussion}

The performed analysis shows that the use of standard altimetry products in the Black Sea, and possibly in a number of other marginal seas, should be treated with some caution. Altimetry missions are focused mainly on reconstruction of the open ocean mesoscale variability, and this applies not only to the resolution of along-track satellite measurements, but also to the location of the tracks themselves in space and time. Pictures taken with only two altimeters (as it was in December 1999) in the orbit allow us to identify satisfactorily the characteristics of eddy formations in the ocean, where the Rossby radius is 40-50 km. However, as shown by the reanalysis results, in the Black Sea, where the Rossby radius is two times smaller, even an improvement in the along-track resolution in some cases will not provide an adequate assessment of the continuous evolution of eddy formations.

This statement demonstrates a map of formal interpolation error provided in the DUACS/CMEMS array. As it can be seen, in the previously mentioned area from $31^{\circ} \mathrm{E}$ to $31.5^{\circ} \mathrm{E}$ this error is $2.5-3$ times higher than that on the way of satellite tracks (Fig. 8).

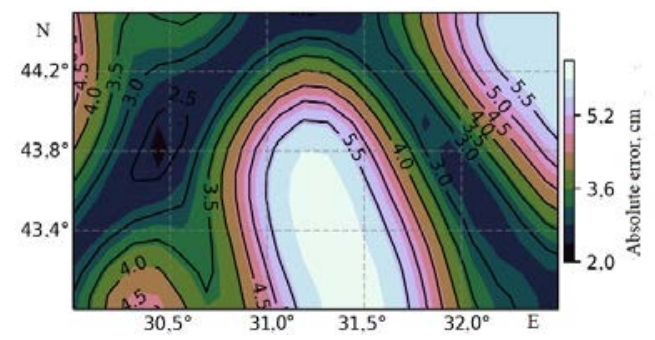

F i g. 8. Formal mapping error (average for December 1-10, 1999) of the DUACS/CMEMS sea level anomaly.

Despite the fact that in subsequent years the number of altimetry missions increased, it is necessary to use the arrays of altimetry observations carefully, especially gridded ones, for assimilation in models and their validation or for analyzing the dynamics of the Black Sea surface layer. When assimilating satellite altimetry observations in the Black Sea circulation model, it is necessary to take into account the structure of possible errors, similar to those shown in Fig. 8.

\section{REFERENCES}

1. Fu, L.-L. and Cazenave, A., eds., 2001. Satellite Altimetry and Earth Sciences: A Handbook of Techniques and Applications. San Diego: Academic Press, 463 p.

2. Fu, L.L. and Le Traon, P.-Y., 2006. Satellite Altimetry and Ocean Dynamics. Comptes Rendus Geoscience, [e-journal] 338(14-15), pp. 1063-1076. https://doi.org/10.1016/j.crte.2006.05.015

3. Ablain, M., Legeais, J.F., Prandi, P., Marcos, M., Fenoglio-Marc, L., Dieng, H.B., Benveniste, J. and Cazenave, A., 2017. Satellite Altimetry-Based Sea Level at Global and Regional Scales. Surveys in Geophysics, [e-journal] 38(1), pp. 7-31. https://doi.org/10.1007/s10712-016-9389-8

4. Morrow, R. and Le Traon, P.-Y., 2012. Recent Advances in Observing Mesoscale Ocean Dynamics with Satellite Altimetry. Advances in Space Research, [e-journal] 50(8), pp. 1062-1076. https://doi.org/10.1016/j.asr.2011.09.033

5. Xu, Y., Li, J. and Dong, S., 2009. Ocean Circulation from Altimetry: Progresses and Challenges. In: J. A. Long, D. S. Wells., Eds., 2009. Ocean Circulation and El Nino: New Research. New York, USA: Nova Science Publishers. Chapter 3, pp. 71-97. Available at: https://www.aoml.noaa.gov/phod/docs/OceanFromAltimetry-Xu_et_al.pdf [Accessed: 30 April 2019]. 
6. Storto, A., Dobricic, S., Masina, S. and Di Pietro, P., 2011. Assimilating Along-Track Altimetric Observations Through Local Hydrostatic Adjustment in a Global Ocean Variational Assimilation

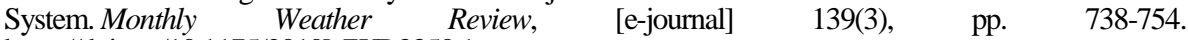
https://doi.org/10.1175/2010MWR3350.1

7. Korotaev, G.K., Oguz, T., Dorofeyev, V.L., Demyshev, S.G., Kubryakov, A.I. and Ratner, Yu.B., 2011. Development of Black Sea Nowcasting and Forecasting System. Ocean Science, [e-journal] 7(5), pp. 629-649. https://doi.org/10.5194/os-7-629-2011

8. Korotaev, G., Oguz, T., Nikiforov, A. and Koblinsky, C., 2003. Seasonal, Interannual, and Mesoscale Variability of the Black Sea Upper Layer Circulation Derived from Altimeter Data. Journal of Geophysical Research, [e-journal] 108(C4), 3122. https://doi.org/10.1029/2002JC001508

9. Kubryakov, A.A. and Stanichny, S.V., 2015. Mesoscale Eddies in the Black Sea from Satellite Altimetry Data. Oceanology, [e-journal] 55(1), pp. 56-67. https://doi.org/10.1134/S0001437015010105

10. V. M. Zhurbas, A. G. Zatsepin, Yu. V. Grigor’eva, V. N. Eremeev, V. V. Kremenetsky, Motyzhev, S.V., Poyarkov, S.G., Poulain, P.-M., Stanichny, S.V. and Soloviev, D.M., 2004. Water Circulation and Characteristics of Currents of Different Scales in the Upper Layer of the Black Sea from Drifter Data. Oceanology, 44(1), pp. 30-43.

11. Béréziat, D., Herlin, I. and Younes, L., 2000. A Generalized Optical Flow Constraint and Its Physical Interpretation. In: IEEE, 2000. Proceedings IEEE Conference on Computer Vision and Pattern Recognition. CVPR 2000 (Cat. No.PR00662). Hilton Head Island, SC: IEEE. Vol. 2, pp. 487-492. doi:10.1109/CVPR.2000.854890

12. Huot, E., Isambert, T., Herlin, I., Berroir, J.-P. and Korotaev, G., 2006. Data Assimilation of Satellite Images Within an Oceanographic Circulation Model. In: IEEE, 2006. 2006 IEEE International Conference on Acoustics Speech and Signal Processing Proceedings. Toulouse: IEEE, pp. II-II. doi:10.1109/ICASSP.2006.1660330

13. Korotaev, G.K., Huot, E., Le Dimet, F.-X., Herlin, I., Stanichny S.V., Solovyev, D.M. and Wu, L., 2008. Retrieving Ocean Surface Current by 4-D Variational Assimilation of Sea Surface Temperature Images. Remote Sensing of Environment, [e-journal] 112(4), pp. 1464-1475. https://doi.org/10.1016/j.rse.2007.04.020

14. Kubryakov, A., Plotnikov, E. and Stanichny, S., 2018. Reconstructing Large- and Mesoscale Dynamics in the Black Sea Region from Satellite Imagery and Altimetry Data - a Comparison of Two Methods. Remote Sensing, [e-journal] 10(2), 239. https://doi.org/10.3390/rs10020239

15. Pujol, M.-I., Faugère, Y., Taburet, G., Dupuy, S., Pelloquin, C., Ablain, M. and Picot, N., 2016. DUACS DT2014: the New Multi-Mission Altimeter Data Set Reprocessed over 20 Years. Ocean Science, [ejournal] 12(5), pp. 1067-1090. https://doi.org/10.5194/os-12-1067-2016

16. Bretherton, F.P., Davis, R.E., Fandry, C.B., 1976. A Technique for Objective Analysis and Design of Oceanographic Experiments Applied to MODE-73. Deep Sea Research and Oceanographic Abstracts, [e-journal] 23(7), pp. 559-582. https://doi.org/10.1016/0011-7471(76)90001-2

17. Kubryakov, A.A. and Stanichny, S.V., 2012. Reconstruction of Mean Dynamic Topography of the Black Sea for Altimetry Measurements. Izvestiya, Atmospheric and Oceanic Physics, [e-journal] 48(9), pp. 973979. https://doi.org/10.1134/S0001433812090095

18. Knysh, V.V., Demyshev, S.G., Inyushina, N.V. and Korotaev, G.K., 2008. Assimilation of Climatic Hydrological Data in a Black-Sea Model Based on the Algorithm of Adaptive Statistics of Prognostic Errors. Physical Oceanography, [e-journal] 18(1), pp. 14-24. https://doi.org/10.1007/s11110-008-9006-6

About the authors:

Artem I. Mizyuk - Senior Research Associate, Marine Hydrophysical Institute of RAS (2 Kapitanskaya Str., Sevastopol, 299011, Russian Federation), Ph. D. (Phys.-Math.), ORCID ID: 0000-0003-4885-354X, ResearcherID: C-6125-2016, artem.mizyuk@mhi-ras.ru

Gennadiy K. Korotaev - Scientific Supervisor, Marine Hydrophysical Institute of RAS (2 Kapitanskaya Str., Sevastopol, 299011, Russian Federation), Corresponding Member of RAS, Dr. Sci. (Phys.-Math.), Professor, ResearcherID: K-3408-2017, gkorotaev@gmail.com.

Contribution of the co-authors:

Artem I. Mizyuk - data acquistion and processing, preparation of graphic materials, intercomparison of SSH data obtained with different types of mean dynmaic topography, numerical procedure for estimation of the sea level from horizontal velocity components, intercomparison of the satellite altimetry and image sequence analvsis data, preparation the paper text.

Gennadiy K. Korotaev - statement of the problem, development of the algorithm of retrieving ocean surface currents from SST image sequence, preparation of the data on ocean surface currents obtained from image sequence analysis, procedure for estimation of the sea level from horizontal velocity components, correction of the paper, consulting support.

All the authors have read and approved the final manuscript.

The authors declare that they have no conflict of interest. 